\title{
Análise comparativa da intervenção fonoaudiológica na surdez: com a família ou com os pais?
}

\author{
Renata Akiyama ${ }^{1}$
}

Akiyama R. Análise comparativa da intervenção fonoaudiológica na surdez: com a família ou com os pais? [dissertação] São Paulo: Faculdade de Medicina, Universidade de São Paulo; 2006.

A confirmação da surdez de uma criança é muito traumatizante para os pais ouvintes e causa grande impacto no sistema familiar, rompendo-se as expectativas e alterando o relacionamento afetivo, social e a comunicação da família com essa criança. A criança surda, devido ao déficit auditivo, terá dificuldades em ouvir os sons da fala e do meio ambiente impossibilitando-a de uma aquisição espontânea e efetiva da língua oral, mas sua comunicação poderá ser efetiva através da Língua de sinais. Por se tratar de famílias ouvintes com crianças surdas nas quais há uma barreira na comunicação e conseqüentemente uma diminuição na interlocução entre os familiares e nas oportunidades sociais e de escolarização dessas crianças, o Programa do Laboratório de Investigação Fonoaudiológica em Audiologia Educacional (LIFAE) do Curso de Fonoaudiologia da Faculdade de Medicina da Universidade de São Paulo oferece as seguintes atividades: terapia fonoaudiológica individual, oficinas de língua de sinais e de língua oral para as crianças surdas, oficinas de língua de sinais para os familiares ouvintes, grupo de suporte aos pais e/ou familiares ouvintes. Este estudo trabalho tem como objetivo verificar o impacto na dinâmica familiar da criança surda, causado por um membro ouvinte que participa diretamente no Programa. Para isso foram entrevistadas 10 famílias sendo que seus membros foram divididos em dois grupos: participantes diretos e participantes indiretos do Programa. Os dados foram analisados quantitativamente através da análise percentual e qualitativamente. Os resultados indicam que os participantes diretos do Programa demonstram ter um envolvimento maior e uma melhor percepção da vida da criança surda. As mudanças relatadas nos depoimentos mostram alterações na dinâmica familiar, ou seja, a comunicação e a interação familiar se modificaram, gerando uma melhora no relacionamento entre os seus membros e na aceitação da surdez, indicando que o Programa é eficaz na intervenção fonoaudiológica a crianças surdas e seus familiares ouvintes.

Trabalho realizado no Departamento de Fisioterapia, Fonoaudiologia e Terapia Ocupacional da Faculdade de Medicina da Universidade de São Paulo - USP - São Paulo (SP), Brasil, para obtenção de título de Mestre em Ciências, sob orientação da Profa. Dra. Ida Lichtig.

(1) Mestre, Colaboradora do Laboratório de Investigação Fonoaudiológica em Audiologia Educacional do Curso de Fonoaudiologia da Faculdade de Medicina da Universidade de São Paulo - USP - São Paulo (SP), Brasil.

Endereço para correspondência: Renata Akiyama. R. Teerã, 497 - Pq. da

Lapa, São Paulo - SP, CEP 05301-000. E-mail: reakiyama@uol.com.br 